\title{
Integration of Gold-Sputtered Electrofluidic Paper on Wire-Included Analytical Platforms for Glucose Biosensing
}

\author{
Estefanía Núnez-Bajo, M. Carmen Blanco-López, Agustín Costa-García, M. Teresa Fernández- \\ Abedul* \\ Departamento de QuímicaFísica y Analítica, Facultad de Química, Universidad de Oviedo, 33006 \\ Oviedo, Spain \\ *e-mail: mtfernandeza@uniovi.es \\ *Tel.: +34985102968
}

\begin{abstract}
This work describes the fabrication and evaluation of an electroanalytical paper-based platform based on the combination of both, reusable and disposable materials in order to generate simple, versatile and low-cost microfluidic devices. With this aim, a holder containing metal wires that act as reusable reference and counter electrodes has been developed. Gold-sputtered paper electrode is disposable and easily interchangeable, meanwhile the platform that includes reference and counter electrodes can be reused. The detection zone in the paper is delimited by drawing a hydrophobic line with an inexpensive permanent marker. The effect of experimental variables such as adding solutions through the face where the gold was sputtered (upwards) or through the opposite one (downwards) as well as of other working parameters were studied by cyclic and differential pulse voltammetry with potassium ferrocyanide as a common redox probe and indicator species for enzymatic, immune and DNA biosensing. Enzymatic determination of glucose in real food samples proves the feasibility of the developed system for the construction of electrochemical biosensors.
\end{abstract}

Keywords: micro paper electroanalytical devices ( $\mu$ PEDs), gold-sputtered electrodes, electrofluidics, wire-based electrodes, glucose 


\section{Introduction}

The use of paper as substrate for analysis has suffered an enormous change since the introduction of microfluidic paper-based analytical devices ( $\mu$ PADs) by Whitesides' group (Martinez et al., 2007, 2010).Qualitative and semiquantitative tests (Comer, 1956) are becoming quantitative assays after integration of appropriate detection systems (Coltro et al., 2014; Cate et al., 2015).The first electroanalytical paper device, with amperometric basis, was developed by Henry’s group (Dungchai et al., 2010). Due to the fact that the electrochemical event in the amperometric mode is surface-based, electrochemistry becomes very appropriate for developing miniaturized, simple and portable analytical platforms since only a small surface is required for the electron transfer. Conductive materials can be easily included on paper or other flat surfaces, in most of the cases in the form of thick or thin films (Metters et al., 2013; Rungsawang et al., 2015; Abad-Valle et al., 2005).When evaluating these devices, productivity-related properties such as analysis time or cost as well as other related to environmental benefits like waste production or energy consumption result very advantageous. Moreover, other basic analytical features (e.g. sensitivity or precision) are generally not compromised. Actually, electrochemical detection leads the field of biosensors from some decades now (Wang et al., 1997; Liu et al., 2007) even employing unexpected electrodes such as the case of common pins (Glavan et al., 2015, Rama et al., 2016). Nowadays, electrochemistry, biosensors and microfluidics have become increasingly linked together (Rackus et al., 2015) and electrochemical paper-based microfluidic devices are having growing interest (Mettakoonpitak et al., 2016). Paper has made possible the integration of electronics and microfluidics, and a new field, “electrofluidics”, has been generated (Hamedi et al., 2016).

Classification of the electrochemical cells could be made based not only on the electrode material (mainly carbonaceous or metallic) or on the shape of the electrodes (film or wire/fiber) but also on their disposition on the paper. Wire, mesh, fiber (Fosdick et al., 2014), pencil leads (Santhiago et al., 2014) or separate screen-printed electrode cards (Noiphung et al., 2013) could be employed in such a way that 
paper contacts the electrodes and serves as a means of transportation of the solution. Porosity of paper arises from spaces between the fibers, un-collapsed fiber lumens and intrinsic pores of the fiber (Pelton, 2009) that could be filled with conductive materials. Then, they can be deposited in one of the paper faces, for example using pencil-drawing techniques (Dornelas et al., 2015) as well as inkjet- (Määttänen et al., 2013) or screen/stencil-printing of conductive inks (Dungchai et al., 2009; Sjöberg et al., 2015). Stencil-free procedures have also been reported with mixed configurations in which carbon ink deposited on paper acts as working electrode and pins of standard electronic connections are employed as reference and counter electrodes (Amor-Gutiérrez et al., 2016).

On the other hand, although really scarce in the bibliography, deposition methods that produce thinfilms seem to be very convenient for porous substrates. Some works on gold sputtering (Shiroma et al., 2012; Ihalainen et al., 2015), electron-beam evaporation (Carvalhal et al., 2010) or spray-deposition (Siegel et al., 2010) have been reported. Although spray-deposition of metal is inexpensive, it gives features with heterogeneous distribution and low conductivity. Sputter deposition can be performed using less expensive equipment (generally associated to scanning electron microscopy facilities) and lower vacuum than e-beam evaporation. Gold sputtering generates thin-film layers that are adequate for performing bioassays, either immunoassays (Abad-Villar et al., 2002, 2003) or DNA assays (Abad-Valle et al., 2005, 2007). Ultrathin gold films (less than $10 \mathrm{~nm}$ ) have been deposited on latex-coated paper for performing electrochemical studies once modified with conductive polymer (Ihalainen et al., 2015).In more complicate designs, carbon or metallic nanomaterials (Hamedi et al., 2016; He et al., 2015; Sun et al., 2015; Li et al., 2014) have been included for obtaining high surface area electrodes.

Among the many well-known advantages that paper possesses, permeability enables also the fabrication of hydrophobic barriers to delimit microchannels for flowing solutions or analytical zones by photolithography (Bruzewicz et al., 2012), inkjet printing (Jokerst et al., 2011), wax printing (Mentele et al., 2012; Wang et al., 2012), wax dipping (Songjaroen et al., 2011) or plotting with permanent markers (Nie 
et al., 2012). Photolithography was the first reported method but expensive instrumentation as well as complicate steps lead to different procedures such as inkjet or wax printing. Although simpler and faster, a printer (linked to a battery supply) and a computer are still needed. Plotting with a permanent marker is a one-step process with no damage to the paper by the composition of solvents that evaporate rapidly. The process can be cleanly performed on-site and in a few seconds without generating residues. In this work, we use a sputtered-gold working electrode in an analytical zone defined by a permanent marker.

Whatman Grade 1 Chromatographic paper is the most employed substrate in paper-based analytical devices. It can be modified for rendering it hydrophobic and allowing an easy deposition of graphite ink using a roller-ball pen (Glavan et al., 2014). However, there are a huge variety of commercial papers whose properties have not been fully exploited. Shiroma et al. employed Whatman P81 (modified with a cation exchanger) for the separation of paracetamol and 4-aminophenol (Shiroma et al., 2012). Here we evaluate different types of paper for electrochemical detection and propose a device that combines the disposability of a gold-sputtered paper working electrode with the reusability of a wire-included plasticbased holder. Moreover, the gold platform can be considered as an electrofluidic platform since flow of electrons and solutions is possible.

One of the main challenges is the design of low-cost but robust and reliable platforms that could be employed for field purposes. Although in most of the cases reported for film electrodes, all the three electrodes are similarly fabricated (e.g., screen-printed), we propose a mixed disposable/reusable approach for generating simple paper amperometric devices. Lu et al. (2012) have reported the use of a transparent device holder with circuit boards and conductive pads in which a folded design included working, in one sheet, and, reference and counter electrodes in the other sheet. In our case, the specific holder is a compact design that contains reference and counter electrodes and allows easy placement of the changeable paper platform avoiding sample evaporation. Wu et al. (2013) employed a multiplex device in 
which several working electrodes shared the same counter and reference electrodes. They were fabricated by screen-printing carbon and silver inks over paper substrates. In our work, external counter and reference electrodes are reused for a huge number of working electrodes. However, these are metal wires instead of paper-based electrodes. Moreover, up to the authors' knowledge, this is the first comparative study on the sputtering coating effectiveness, robustness and electrochemical behavior of both gold-sputtered and wire electrodes. Ferrocyanide has been employed as a well-known redox probe, although is commonly employed for enzymatic sensing (Rama et al., 2016) as well as for immuno (Cai et al., 2016) and DNA (Shahrokhian, 2016) biosensing.

As a proof-of-concept, we tested the feasibility of the system to measure the concentration of glucose, a relevant analyte in clinical and food fields. Glucose was detected chronoamperometrically, after enzymatic reaction with glucose oxidase and horseradish peroxidase, using ferrocyanide as electron-transfer mediator. Ferricyanide is enzymatically generated and electrochemically reduced on the gold-sputtered paper based electrode. This allows reducing drastically the volume, reaction time and cost of analysis. The accuracy of the results obtained using the wire-based plastic-holder and gold-sputtered paper-based electrodes for glucose determination in commercial drinks was evaluated by comparison with results obtained using a commercial kit with spectrophotometric detection.

2.Materials and methods

2.1 Chemicals, materials and apparatus

Potassium ferrocyanide trihydrate $\left(\mathrm{K}_{4}\left[\mathrm{Fe}(\mathrm{CN})_{6}\right] \cdot 3 \mathrm{H}_{2} \mathrm{O}\right)$, glucose oxidase from Aspergillus (GOx), horseradish peroxidase, Type VI-A (HRP), glucose assay kit (GAGO20) and Trizma base were purchased from Sigma-Aldrich (USA). Sodium hydroxide, potassium chloride, ortophosphoric acid (90\%) and D(+)-Glucose anhydrous were supplied by Merck. All the solutions were prepared in Milli-Q water (Merck Millipore). Working solutions of potassium ferrocyanide were prepared daily in $0.1 \mathrm{M}$ phos- 
phate buffer $\mathrm{pH} 7.0(0.1 \mathrm{M} \mathrm{KCl})$. Glucose solutions as well as those of GOx/HRP/ferrocyanide were prepared daily in $0.1 \mathrm{M}$ Tris- $\mathrm{HNO}_{3}$ buffer $\mathrm{pH}$ 7.0.

Whatman Chromatographic papers Grade 1 and 3MM, ionic exchangers (P81 and DE81) and glass fiber GF/F were obtained from GE Healthcare Life Sciences (UK), polyester PTR-R5 and glass fiber GFBR7L from Mdi (India) and Hi Flow (nitro) paper from Merck Millipore (Germany). 100- $\mu$ Mdiameter gold wire and, 100 and $250 \mu \mathrm{m}$-diameter platinum wires were purchased from AlfaAesar (USA). Conductive copper tape was provided by Electron Microscopy Sciences (USA). Transparency sheets and permanent marker (EBBE) were acquired from local stationeries.

A Sputtering DC model CD 004 from Balzers (Germany) was employed for gold deposition. Electrochemical measurements were made using an Autolab PGSTAT potentiostat model (PGSTAT12) from Metrohm (USA). A Mettler Toledo (AB54) balance (USA), a Crison Micro-pH 2001 pH-meter (Spain), a magnetic stirrer Asincro (J.P.Selecta, Spain), Digital Multimeter Model (DT9205A) were also employed.

\subsection{Preparation of Gold Paper-based Electrodes}

We have drawn hydrophobic lines with a permanent marker delimiting $10 \mathrm{~mm} \times 10 \mathrm{~mm}$ squares that define the working zone on all the paper substrates. These were cut according to the sputtering camera dimensions into $60 \mathrm{~mm} \times 75 \mathrm{~mm}$ pieces. Squares were drawn in both sides with the aid of a ruler as illustrated in Figure 1A. After solvent evaporation at room temperature, an adhesive plastic mask with a pattern of three similar slits $(1 \mathrm{~mm} \times 20 \mathrm{~mm}$ with $1 \mathrm{~mm}$ in between $)$ was positioned at the center of the substrate. In addition, another plastic sheet was located under the paper as backing protective layer (Figure 1B). This "sandwich" was covered with gold by a sputtering process. Gold atoms were deposited (from the cathode) over the paper placed on the anode through the slits in a vacuum chamber filled with argon. The thickness of the gold layer was controlled by the duration and intensity of the discharge. 
For a thin film, a $20 \mathrm{~mA}$ discharge was applied over $240 \mathrm{~s}$. Then, the mask was removed and $25 \mathrm{~mm} \mathrm{x}$ $15 \mathrm{~mm}$ paper-based platforms containing three gold lines where cut (Figure 1C). An adhesive copper foil (40mmx1mm) was employed to connect gold electrodes to the potentiostat (Figure 1D and 1E). All the three lines can be part of the potentiostatic electrochemical cell, or alternatively, metal wires included in a plastic holder can be employed instead, together with one paper-based electrode.

\section{FIGURE 1}

Solutions can be added through the face where the gold was deposited (upward configuration) or the opposite one (downward configuration). Adhesive tape was used to ensure the fixation of the cupper film and avoid liquid dispersion. Alligator clips were clamped in the cupper at a distance of $25 \mathrm{~mm}$ to connect electrodes to the potentiostat. When the electrochemical cell is based uniquely on sputtered electrodes (working electrode at the middle), tape is also placed under the paper (Figure 1D for upward and $1 \mathrm{E}$ for downward modes). When the holder including metal wires was employed, no tape was needed since solutions passed through the porous paper connecting upper paper-based electrodes (upward mode) to bottom wire-based electrodes. However, in the downward mode, tape was is always required at the bottom (using or not the holder).

\subsection{Fabrication of the Wire-included Plastic Holder}

Two different designs for a three-electrode system based on the combination of sputtered and wirebased electrodes were proposed. Depending on the position of the paper-based electrode, upwards (sputtered lines are in the upper part of the paper in direct contact with solutions and wire electrodes are at the bottom) or downwards (wire electrodes are in the upper part and sputtered lines are at the bottom; contact with solutions occurs by capillarity). The open structure and dimensions of the upward design are shown in Figure 2A. First, the shape was trimmed on a transparency sheet and gold and platinum wires were sewn through four pinholes created at a distance of $2 \mathrm{~mm}$. The tabs (i) fit into slits (ii) facili- 
tating the full closure in such a way that the central part of the wires were inside the structure, while their ends were outside as shown in Figure 2B. Copper tape was used for connection to the potentiostat (at opposite sides for avoiding short-circuits) through alligator clips. Once the holder is closed, the slit in the center of the structure (iii in Figure 2A) allows the insertion of the paper-based electrode (Figure 2B). In this case, only the central gold-sputtered line was employed. Solutions contact the paper through the pinhole created in the upper part. Otherwise, the design for downward mode would have few variations respect the upward one. Since the paper-based electrode is in the bottom, wires have to be in the upper part, close to the injection hole. Both designs can be made in the same plastic box only by opening an injection hole at both sides.

\section{FIGURE 2}

\subsection{Electrochemical Measurements}

Cyclic voltammetry (CV) and differential pulse voltammetry (DPV) were performed with different electrochemical cells and various configurations of paper- and wire-based electrodes (working (WE), reference (RE) and counter (CE) electrodes) were employed. Potential was scanned from -200 mV to 400 $\mathrm{mV} v s$. the pseudo-reference electrode in both cyclic and differential pulse voltammetric experiments. $\mathrm{CV}$ was performed at a scan rate of $50 \mathrm{mV} \cdot \mathrm{s}^{-1}$. Pulse amplitude of $25 \mathrm{mV}$ and step potential of $5 \mathrm{mV}$ were employed in DPV.

\subsection{Scanning Electron Microscopy Study}

The topography of selected paper substrates was examined by Scanning Electron Microscopy (SEM). For these studies, specimens were prepared by placing the sample paper on aluminum stubs covered with carbon double-sided adhesive tape. Samples, conductive enough, are placed perpendicularly to the electron beam with a working distance of $10 \mathrm{~mm}$ and $20 \mathrm{kV}$ of extraction tension, in a JEOL (model 6610LV) microscope. 
The procedure for measuring the concentration of glucose was as follows. First of all, a mixture of GOx, $\mathrm{HRP}$, and ferrocyanide $\left(1.6 \mathrm{U} / \mu \mathrm{L}, 2.5 \mathrm{U} / \mu \mathrm{L}\right.$ and $0.1 \mathrm{M}$, respectively) in $0.1 \mathrm{M}$ Tris- $\mathrm{HNO}_{3}$ buffer $\mathrm{pH} 7.0$ was prepared. Then, $2.5 \mu \mathrm{L}$ of this mixture were added to each gold-sputtered paper-based electrode leaving to dry for 10 minutes before adding $2.5 \mu \mathrm{L}$ of glucose-content solutions. Thus, glucose concentration was determined measuring chronoamperometrically the concentration of enzymaticallygenerated ferricyanide. For each mole of glucose, two moles of ferrocyanide are oxidized to ferricyanide (Bankar et al., 2009; Ruzgas et al. 1996). Applying -0.2 V versus the gold wire pseudo-reference electrode, the ferricyanide was reduced and the measured current was proportional to the concentration of ferricyanide enzymatically generated, and in turn, to the concentration of glucose in solution. Glucose concentration was measured in five real food samples (orange juice and zero cola, cola and energetic beverages). The only sample treatment needed was a dilution in $0.1 \mathrm{M}$ Tris- $\mathrm{HNO}_{3}$ buffer $\mathrm{pH}$ 7.0. In order to test the accuracy of the results obtained, the samples were also analyzed using a commercial glucose kit with spectrophotometric detection.

\section{Results and discussion}

\subsection{Electrochemical Behavior of Gold-Sputtered Paper-based Electrodes}

Although carbon electrodes were the first choice for $\mu$ PADs (Table 1), gold electrodes are very advantageous for modification with bioreceptors or self-assembled monolayers prior device assembly (AbadValle et al., 2007). Screen and inkjet carbon printing (Dungchai et al., 2009; Kit-Anan et al., 2012) are both considered thick-film technologies. This can be relevant because hydrophilicity can be changed by the production of more dense hydrophobic structures that in some cases could impede the advance of flow. This happens when carbon ink is deposited in a maskless procedure employing a micropipette tip (Amor-Gutiérrez et al., 2016). Here the solution is added by the opposite hydrophilic paper part. Car- 
bon-based pencils were fabricated with conductive, binding, hardening as well as modifying agents, and could contact externally the paper (Santhiago et al., 2013) or hand-drawing be employed to transfer the conductive material into the paper (Dossi et al., 2014). Graphite ink can be dispensed on silanized paper using a pen-on-paper approach through a roller-ball pen installed in the blade-set of an electronic craft cutter producing more equal ink application and electrode geometry (Glavan et al., 2014). Gold sputtering is thin-film technology and flow of solutions is not impeded. It can also be deposited on almost any surface, hydrophilic or hydrophobic. Carbon-based nanomaterials were also employed in free-standing structures (Sun et al., 2015) and for generating electrofluidic systems (Hamedi et al., 2016), which is also possible through gold sputtering.

\section{TABLE 1}

Then, the first designs employed were three-electrode potentiostatic systems with all-in-paper goldsputtered electrodes (working, reference and counter electrodes). Fabrication is illustrated in Figure 1. A permanent marker is employed for generating a hydrophobic barrier and delimiting the working area (Figure S1A). Drawing $10 \mathrm{~mm}$ x $10 \mathrm{~mm}$ squares in both sides of the paper with permanent markers, water-resistant barriers that avoid liquid dispersion from the cell are generated (Figure S1A top). Similarly, hydrophobicity does not allow liquids enter the working area (Figure S1A bottom). Connections, especially in miniaturized systems, are of great relevance. Adhesive copper film, acts as a contact between the sputtered gold and a clip that connects to the potentiostat (Figure S1C).

Devices were characterized using Whatman Grade 1 chromatographic paper and a $2 \mathrm{mM}$ solution of $\mathrm{K}_{4} \mathrm{Fe}(\mathrm{CN})_{6}$ in $0.1 \mathrm{M}$ phosphate buffer(PB) $\mathrm{pH} 7.0,0.1 \mathrm{M}$ in $\mathrm{KCl}$, as well-known redox probe (Kubota et al., 1992). The solution was deposited either by the side where the sputtering was made (upwards) or the opposite one (downwards). Five cyclic voltammograms were recorded at $50 \mathrm{mV} \mathrm{s}^{-1}$ (each one taking 24 s), just after addition of $7 \mu \mathrm{L}$ of the solution that distributed rapidly through the paper up to the hydro- 
phobic line of the permanent marker. The process of the ferro/ferri system is shown in the CVs of Figure S2. In both cases, up and downward modes, an almost reversible process takes place, with a difference between anodic and cathodic potentials of $120 \mathrm{mV}$. The ratio between anodic and cathodic peak currents (absolute value) is 0.90.Precise analytical signals were obtained during $120 \mathrm{~s}$ at room temperature, indicating a stable electrochemical system (Figure S3). On the other hand, in the upward mode, currents were at least twice more intense. Access to the electrode surface is higher in the upward mode, and we used this configuration for the remainder of work.

With the aim of evaluating the precision, five electrochemical cells made on different sputtering processes were checked (Table S1). The RSD obtained for the upward configuration, is 11 and $9 \%$ for anodic and cathodic peak currents respectively (average peak currents of 2.44 and $-2.74 \mu \mathrm{A}$ ). The ratio $\mathrm{i}_{\mathrm{pa}} / \mathrm{i}_{\mathrm{pc}}$ is $0.89 \pm 0.07$ and the peak potential varies 43 and $11 \mathrm{mV}$ for the anodic and cathodic processes respectively.

\subsection{Electrochemical Cell with Paper and Wire Electrodes}

In an electrochemical cell, not only the working electrode is important but also the reference (especially in miniaturized systems where pseudo-references are employed) and the counter electrode. In order to have a robust electroanalytical platform, we designed a plastic holder that includes wires that can act as electrodes (see Figure 2). In this way, the only movable element is the paper-based electrode, being the rest fixed and common to all the devices. It could be used then with several paper substrates, constituting a fully integrated electroanalytical platform. This is very important for approaching real portable platforms for biosensing. The holder is fabricated using a piece of a transparency sheet that has im-

portant advantages: i) low cost, ii) foldability, iii) hydrophobicity and (iv) durability. The holder has also different functions: i) contains the wires that act as reference and counter electrodes, ii) maintains the paper wet avoiding evaporation without damaging the gold film, iii) gives stability to the platform 
generating a user-friendly interface and, iv) improves the precision. To evaluate it, electrochemical cells coming from different sputtering batches were characterized. In this case, the central gold-sputtered paper-based electrode acted as working and, gold and platinum wires as reference and counter electrodes, respectively. Although two different configurations, upwards and downwards, are possible (Figure $2 \mathrm{~B}$, top and bottom respectively), only the upward mode was employed. In this configuration, wires are located at the bottom and the sputtered-gold film is wet enough when the solution arrives to the bottom, connecting all the three electrodes. In the downward mode the wires are at the top and the solution connects through the paper the internal face of the sputtered gold. In both cases, wires and gold film are separated by the thickness of the paper sheet.

The RSD for five devices fabricated in different batches (Table S2) and checked in the same holder is 4 and $6 \%$ for anodic and cathodic processes, respectively, and the ratio $i_{p a} / i_{p c}$ is $1.22 \pm 0.03$, with average peak currents of 3.25 and $-3.18 \mu \mathrm{A}$. Peak potentials for the anodic process in the different cells varies $10 \mathrm{mV}$, meanwhile in the cathodic process variation is $13 \mathrm{mV}$. In addition, higher reversibility is observed since the difference between anodic and cathodic potentials is $70 \pm 3 \mathrm{mV}$.

\section{FIGURE 3}

In order to know the nature of the redox probe process, the dependence of the peak current on the scan rate for $2 \mathrm{mM} \mathrm{K} \mathrm{K}_{4} \mathrm{Fe}(\mathrm{CN})_{6}$ solutions was evaluated. $\mathrm{CV}$ scans were recorded for three different paper substrates (Figure 3A), repeating the scan three times for each paper electrode. Washings ( $3 \times 15 \mu \mathrm{L}$ of Milli-Q water) and dryings were performed in between scans. A linear relationship is found when peak cur-

rents are represented vs. the square root of the scan rate between 10 and $100 \mathrm{mV} . \mathrm{s}^{-1}$ (Figure 3B). Randles and Sevcik indicated that reversible processes under mass transfer regime of semi-infinite diffusion control follow a linear relationship (Randles, 1948; Sevcik, 1948). Slopes of the equations of log $\mathrm{i}_{\mathrm{p}} v s . \log \mathrm{v}$ are 0.43 and 0.51 for anodic and cathodic processes respectively. However, it can be seen 
that the CVs have lower separation of peak potentials at lower scan rates (Figure S4, from 27 to $74 \mathrm{mV}$ when scan rate moves from 10 to $100 \mathrm{mV} \cdot \mathrm{s}^{-1}$ ), which can be indicative of the introduction of kinetic control on the shorter time scale or a small amount of uncompensated resistance. In any case, we are working with porous electrodes and probably different contributions are present (Streeter et al., 2008).

Although in this study paper-based electrodes were reused, their low-cost makes possible to consider them as single-use devices, and accordingly, we avoided washing and reusing them for the rest of experiments.

\subsection{Wire-Holder with different Paper Substrates}

Although Whatman Grade 1 Chromatographic paper is commonly used, there are several commercial filter papers (Grade 3MM, P81, DE81, GF/F from Whatman and membranes PT-R5 and GFB-R7L from Mdi, as well as the Millipore Hiflow Plus) with different physical and chemical properties (Table S3).

Whatman Grade 3MM has different thickness but the same composition, cellulose, than Grade 1. Whatman GF/F and Mdi GFB-R7L are made of glass fiber and Mdi PT-R5 of polyester, and therefore, their wettability and capillary flow are different. Whatman P81 and DE81 are cellulosic papers modified with cation and anion exchangers, based on phosphate and diethylaminoethyl groups respectively. Nitrocellulose Millipore HF Plus membrane allows capillary transport of solutions at high flow rates.

\section{FIGURE 4}

In order to correlate the voltammetric behavior with the fiber microstrucure we studied paper substrates by Scanning Electron Microscopy (SEM). As shown in Figure 4A, papers based on pure cellulose (Whatman 1 and 3MM) present similar heterogeneous distribution of fibers with irregular width. Partial modification with functional groups like phosphate (P81) and diethylaminoethyl (DE81) produces conglomerates which decrease the number of porous zones while nitrocellulose seems to be more homogeneous (HF) with smooth surface and a high number of smaller porous zones, producing high capillary 
flow rates. In contrast to cellulosic materials, rigidity of polyester (PT) fibers increases the paper robustness but their distribution generates higher dead volume, which makes difficult generating uniform and effective hydrophobic barriers by using a permanent marker. Finally, glass fiber substrates showed a tangle of thin and flexible fibers too fragile and porous, which results in complicate handling and creation of ineffective hydrophobic barriers (Figure S1B).

The characteristics of substrates also condition the depth and adhesion of gold atoms and the resolution of the lines obtained (when the three-line mask is employed). Cellulose-type substrates exhibit welldefined lines and brighter lines were obtained on Millipore Hi-Flow Plus substrate and PT-R5 membranes. In the last one, gold atoms penetrated deeper because of the higher dead volume, but resolution of the lines was not as good as in the cellulosic substrates. Taken all of this into account, we considered cellulose-based papers (Chr 1, 3MM, P81, DE81Whatman papers and Millipore Hi-Flow Plus) appropriate for fabricating gold-sputtered based electroanalytical devices. Polyester-based devices were also prepared regardless the lower barrier effectiveness and the poorer resolution of the gold-sputtered lines, for the sake of comparison between analytical signals.

Gold-sputtered paper-based electrodes were fabricated with the three-line mask. In this case, the central line acted either as working electrode (Au wire as RE and Pt wire as $\mathrm{CE}$ ), reference (Au wire as WE and Pt wire as CE) or counter electrode (Au wire as RE and Pt wire as WE) in upward configuration. Similarly, gold and platinum wires were checked as WE. The study was carried out measuring the anodic peak currents of differential pulse voltammograms recorded in $2 \mathrm{mM}$ ferrocyanide solution $(0.1 \mathrm{M}$ PB buffer, $\mathrm{pH} 7.0,0.1 \mathrm{M} \mathrm{KCl})$. Scans of five devices were recorded for each substrate in each configuration (a total of fifteen devices for each paper substrate were evaluated). Results, represented in a bar diagram in Figure 4B, show the most intense currents when gold-sputtered paper-based electrode acts as working electrode for all the substrates except for the nitrocellulose-based HF, where higher currents were obtained using gold wire as WE. The second highest is the one in which the paper acts as reference. This 
could be due to the smaller distance between RE and WE and thus, the minimization of the ohmic drop. In the combination of gold-sputtered line (WE/RE) and gold wire (RE/WE) the distance is equal or lower than the thickness of the substrate (less than $500 \mu \mathrm{m}$ ) but in the case of the combination of both wires, gold as RE and platinum as WE, they were at $2 \mathrm{~mm}$ of distance. In this last case, the sputtered line acts as counter electrode and the lowest signals were obtained.

Poor results observed in polyester-type substrates were probably due to the distance between fibres and the rigidity that could impede the proper formation of continuous and conductive gold lines. Results are in accordance to ohmic-resistance measurements carried out with a multimeter in $2 \mathrm{~mm}$ sections of gold-sputtered lines in four different devices (Table S4) with the highest resistance found for PT-R5.On the other hand, the thickness of nitrocellulose-based HF paper and Whatman Grade 3MM makes these substrates unsuitable for the construction of gold-sputtered electrodes. The first material is too thin (130 $\mu \mathrm{m})$ and fragile, producing short circuits in many cases. The second one is too thick $(340 \mu \mathrm{m})$ and similarly to what happens with PT substrate (also more than $300 \mu \mathrm{m}$-thick) the signal is lower than the one obtained for thinner substrates (except for the fragile HF). Pure or partially modified (with ion exchangers) cellulose papers are the most adequate substrates for the construction of working electrodes because their smooth surface allows the generation of more conductive lines. Intermediate thickness (between 180 and $230 \mu \mathrm{m})$ generates devices that are robust enough and favor electrochemical processes lowering the WE-RE distance. Even being ferrocyanide an anion, variation in the signal obtained for papers modified with cation (P81) and anion (DEAE) exchangers were not significant, although differences in precision were observed.

Several Whatman Chr 1 gold-sputtered electrodes were prepared and included in the holder with metal wires (RE and $\mathrm{CE}$ ) in order to evaluate the response to the concentration of ferrocyanide, from 0.5 to 3 mM. In Figure 5A anodic peaks of cyclic voltammograms for different concentrations as well as the calibration curve (each point is the average for three different paper substrates) are shown. Equations for 
anodic and cathodic peak currents, $\mathrm{i}_{\mathrm{pa}} / \mu \mathrm{A}=0.7961 \mathrm{C} / \mathrm{mM}+1.6745$ and $\mathrm{i}_{\mathrm{pc}} / \mu \mathrm{A}=-1.0365 \mathrm{C} / \mathrm{mM}-0.9515$, respectively, presented good linearity $\left(\mathrm{R}^{2}>0.993\right)$.

\section{FIGURE 5}

To increase the analytical signal, five different devices whose surface was coated completely with gold by a sputtering process at $20 \mathrm{~mA}$ for $240 \mathrm{~s}$ were evaluated. Dimensions for the sputtered (15 $\mathrm{cm} \times 20$ $\mathrm{cm})$ and analytical $(10 \mathrm{~mm} \times 10 \mathrm{~mm})$ zones were the same as those employed in previous studies. Peak currents recorded in a $2 \mathrm{mM}$ ferrocyanide solution $(200 \pm 16 \mu \mathrm{A})$ were more than 100 times higher that in previous paper electrodes (Table S5).

Good interelectrode precision indicates this platform could be applied for biosensing and field analysis as a commercial reusable platform with disposable low-cost materials. Depending on the analyte or application other cellulosic substrates can be employed without important increment in costs. Anestimation of the cost per device is included in the Supplementary Information (Table S6). The higher cost is attributed to platinum wire (\$2.24 for the wire employed in the holder, with a cost of $\$ 112$ for $1 \mathrm{~m}$ of a $0.1 \mathrm{~mm}$ wire). It decreases to $\$ 0.38$ when the material is changed by stainless steel. In this case, the cost is such that excluding labor and capital expenses, a holder with ten disposable paper electrodes costs less than $\$ 4$ (estimated costs of the paper-based electrode and the holder are $\$ 0.23$ and $\$ 1.65$ respectively).

\subsection{Glucose Determination: Calibration and Real Sample Analysis}

To simplify the fabrication process of gold-sputtered electrodes, rectangles of $5 \mathrm{~mm}$ x $20 \mathrm{~mm}$ containing analytical working areas of $5 \mathrm{~mm}$ x $5 \mathrm{~mm}$ were prepared drawing with permanent marker and coating with gold as previously described (see Figure S5). The feasibility of the wire-based plastic-holder combined with gold-sputtered paper-based electrodes to measure the concentration of glucose in real samples was evaluated. In this way, a bienzymatic assay employing glucose oxidase (GOx), horseradish 
peroxidase (HRP), and ferrocyanide, used as mediator of the electron transfer, was performed. The reaction occurs for $30 \mathrm{~s}$ at the same time the chronoamperogram is recorded at $-0.2 \mathrm{~V}$ vs. gold-wire pseudoreference electrode. A cyclic voltammogram was previously recorded in order to choose the detection potential. Figure 5B shows the calibration curves performed in three different days for the measurement of glucose concentrations comprised between 0.1 and $15 \mathrm{mM}$. Linear relationship was obtained with a $\mathrm{R}^{2}=0.9977$. The average slope and intercept were $-1.11 \pm 0.03 \mu \mathrm{A} \cdot \mathrm{mM}^{-1}$ and $-1.08 \pm 0.5 \mu \mathrm{A}$, respectively. The limit of detection (LOD) calculated according to $3 \mathrm{~S}_{\mathrm{b}} / \mathrm{m}$ criterium, where $\mathrm{m}$ is the slope of the linear range and $\mathrm{S}_{\mathrm{b}}$ the standard deviation of the background (signal without glucose), was $0.11 \mathrm{mM}$

Five real samples (one of them considered as negative control, with a glucose concentration under the detection limit) were analyzed using the developed paper and wire-based electrochemical platform and the results were compared with those obtained using a commercial glucose kit with spectrophotometric detection (see Figure S6). Table 2 shows the results obtained by both methods. The application of the tStudent's test demonstrated that there were no significant differences between the values given by the commercial kit and those obtained with our paper and wire-based electrochemical system at a 0.05 significance level. This indicates the good accuracy and precision achieved.

\section{TABLE 2}

\section{Conclusions}

We have presented a robust platform to use with paper-based working electrodes. The combination of a reusable plastic holder with wires included and a disposable gold-sputtered piece of paper provides the basis for the fabrication of electroanalytical devices very promising for use in biosensing and field analysis. Apart from reusability, our holder has several main advantages: i) it is inexpensive (metal wires are reusable and the paper electrode has a thin gold film), ii) it is lightweight and flat, being portable, easily stored (even in open format), easy to use and very appropriate for field analysis, iii) it is made of hydro- 
phobic material and then cleaning is easily made, iv) it acts as a cover that avoids evaporation of solutions, v) it is a user-friendly interface between disposable paper and potentiostat, vi) it is versatile since it could be used with many different flat substrates and, vii) it is market-friendly, a unique holder can be used with many different single devices.

Although Au and Pt wires are intended to be reused, they are easily interchangeable. The paper substrate could be very different and thickness is a characteristic to have in mind; $150-250 \mu \mathrm{m}$ thick papers seem to be the most appropriate.

We have demonstrated its potential for glucose bienzymatic sensing. The enzymes are immobilized by adsorption on the gold paper-based surface and the current due to the reduction of the mediator (ferrocyanide) is the analytical signal, measured at $50 \mathrm{~s}$. The biosensor shows a wide concentration range and very precise calibration graphs when performed in different days. Glucose was determined in real food samples with good accuracy, which encourages us to extend its use to different applications.

\section{Acknowledgements}

This work has been supported by the Spanish Ministry of Economy and Competitiveness (MINECO) under projects CTQ2011-25814 and CTQ2014-58826-R. Estefania Nunez-Bajo thanks MINECO for the award of a PhD grant BES-2012-056713.

\section{Supplementary Information}

Supplementary data associated with this article can be found in the online version at http://dx.doi.org.

\section{Bibliography}

Abad-Valle, P., Fernández-Abedul, M.T., Costa-García, A., 2007. Biosens. Bioelectron. 22, 1642-1650. doi:http://dx.doi.org/10.1016/j.bios.2006.07.015 
Abad-Valle, P., Fernández-Abedul, M.T., Costa-García, A., 2005. Biosens. Bioelectron. 20, 2251-2260. doi:10.1016/j.bios.2004.10.019

Abad-Villar, E.M., Fernández-Abedul, M.T., Costa-García, A., 2003. Anal. Bioanal. Chem. 377, 26772. doi:10.1007/s00216-003-2122-8

Abad-Villar, E.M., Fernández-Abedul, M.T., Costa-García, A., 2002. Biosens. Bioelectron. 17, 797802. doi:10.1016/S0956-5663(02)00080-5

Adkins, J., Boehle, K., Henry, C., 2015. Electrophoresis 36, 1811-1824. doi:10.1002/elps.201500084

Amor-Gutiérrez, O., Rama, E.C., Costa-García, A., Fernández-Abedul, M.T., 2016. Biosens. Bioelectron. (in press). doi: 10.1016/j.bios.2016.11.008.

Apilux, A., Dungchai, W., Siangproh, W., Praphairaksit, N., Henry, C.S., Chailapakul, O., 2010. Anal. Chem. 82, 1727-1732. doi:10.1021/ac9022555

Bankar, S.B., Bule, M. V., Singhal, R.S., Ananthanarayan, L., 2009. Biothecnol. Adv. 27, 489-501. doi: 10.1016/j.biotechadv.2009.04.003

Bruzewicz, D. A., Reches, M., Whitesides, G.M., 2012. Changes 29, 997-1003. doi: 10.1021/ac702605a.

Cai, X., Weng, S., Guo, R., Lin, L., CHen, W., Zheng, Z., Huang, Z., Lin, X., 2016. Biosens. Bioelectron., 81, 173-180. doi:10.1016/j.bios.2016.02.066

Carvalhal, R.F., Kfouri, M.S., De Piazetta, M.H.O., Gobbi, A.L., Kubota, L.T., 2010. Anal. Chem. 82, 1162-1165. doi:10.1021/ac902647r

Cate, D.M., Adkins, J. A, Mettakoonpitak, J., Henry, C.S., 2015. Anal. Chem. 87, $19-41$. doi:10.1021/ac503968p 
Coltro, W.K.T., Cheng, C.M., Carrilho, E., de Jesus, D.P., 2014. Electrophoresis 35, 2309-2324. doi:10.1002/elps.201400006

Comer I. P., 1956. Anal. Chem. 28, 1748-50. doi:10.1021/ac60119a030

Dornelas, K.L., Dossi, N., Piccin, E., 2015. Anal. Chim. Acta 858, 82-90. doi:10.1016/j.aca.2014.11.025

Dossi, N., Impellizzieri, F., Toniolo, R., Bontempelli, G., 2014. J. Electroanal. Chem. 722-723, 90-94.

Dungchai, W., Chailapakul, O., Henry, C.S., 2009. Anal. Chem. 81, 5821-5826. doi:10.1021/ac9007573

Dungchai, W., Chailapakul, O., Henry, C.S., 2011. Analyst 136, 77-82. doi:10.1039/c0an00406e

Fosdick, S.E., Anderson, M.J., Renault, C., Degregory, P.R., Loussaert, J. A., Crooks, R.M., 2014. Anal. Chem. 86, 3659-3666. doi:10.1021/ac5004294

Glavan, A.C., Ainla, A., Hamedi, M.M., Fernández-Abedul, M.T., Whitesides, G.M., 2015. Lab Chip 16, 112-119. doi:10.1039/C5LC00867K

Glavan, A.C., Christodouleas, D.C., Mosadegh, B., Yu, H.D., Smith, B.S., Lessing, J., FernándezAbedul, M.T., Whitesides, G.M., 2014. Anal. Chem. 86, 11999-2007. doi:10.1021/ac5020782

Hamedi, M.M., Ainla, A., Guder, F., Christodouleas, D.C., Fernández-Abedul, M.T., Whitesides, G.M., 2016. Adv. Mat., 28 (25) 5054-5063. doi: 10.1002/adma.2015.05.823

He, W., Sun, Y., Xi, J., Abdurhman, A.A.M., Ren, J., Duan, H., 2015. Anal. Chim. Acta 903, 61-68. doi:10.1016/j.aca.2015.11.019

Ihalainen, P., Määttänen, A., Pesonen, M., Sjöberg, P., Sarfraz, J., Österbacka, R., Peltonen, J., 2015. Appl. Surf. Sci. 329, 321-329. doi:10.1016/j.apsusc.2014.12.156 
Jokerst, J.C., Adkins, J. a, Bisha, B., Mentele, M.M., Goodridge, L.D., Henry, C.S., 2012. Anal. Chem. 84, 2900-2907. doi: 10.1021/ac203466y.

Kim, B., Lu, Y., Kim, T., Han, J., Meyyappan, M., Li, J., 2014. ACS Nano 0-5. doi:10.1021/nn5037653

Kubota, L. T., Gushiem, Y., 1992. Electrochim. Acta 37, 2477-2480. doi:10.1016/0013-4686(92)87087G.

Li, L., Li, W., Yang, H., Ma, C., Yu, J., Yan, M., Song, X., 2014. Electrochim. Acta 120, $102-109$. doi:10.1016/j.electacta.2013.12.076

Liu, F., Ge, S., Yu, J., Yan, M., Song, X., 2014. Chem. Commun. 50, 10315. doi:10.1039/C4CC04199B

Liu, Q., Lu, X., Li, J., Yao, X., Li, J., 2007. Biosens. Bioelectron. 22, 3203-3209. doi:10.1016/j.bios.2007.02.013

Lu, J., Ge, S., Ge, L., Yan, M., Yu, J., 2012. Electrochim. Acta 80, 334-341. doi:10.1016/j.electacta.2012.07.024

Määttänen, A., Vanamo, U., Ihalainen, P., Pulkkinen, P., Tenhu, H., Bobacka, J., Peltonen, J., 2013. Sens. Actuator., B Chem. 177, 153-162. doi:10.1016/j.snb.2012.10.113

Martinez, A.W., Phillips, S.T., Butte, M.J., Whitesides, G.M., 2007. Angew. Chemie - Int. Ed. 46, 1318-1320. doi:10.1002/anie.200603817

Mentele, M.M., Cunningham, J., Koehler, K., Volckens, J., Henry, C.S., 2012. Anal. Chem. 84, 44744480. doi:10.1021/ac300309c

Mettakoonpitak, J., Boehle, K., Nantaphol, S., Teengam, P., Adkins, J.A., Srisa-Art, M., Henry, C.S., 2016. Electroanalysis, 28, 1420-1436. doi: 10.1002/elan.201501143

Metters, J.P., Houssein, S.M., Kampouris, D.K., Banks, C.E., 2013. Anal. Methods 5, $103-110$. 
doi:10.1039/c2ay26396c

Nie, J., Zhang, Y., Lin, L., Zhou, C., Li, S., Zhang, L., Li, J., 2012. Anal. Chem. 84, 6331-6335. doi:10.1021/ac203496c

Noiphung, J., Songjaroen, T., Dungchai, W., Henry, C.S., Chailapakul, O., Laiwattanapaisal, W., 2013. Anal. Chim. Acta 788, 39-45. doi:10.1016/j.aca.2013.06.021

Pan, S., Deen, M.J., Ghosh, R., 2015. Anal. Chem. 151012110802007. doi:10.1021/acs.analchem.5b03164

Pelton, R., 2009. TrAC - Trends Anal. Chem. 28, 925-942. doi:10.1016/j.trac.2009.05.005

Rama, E.C, Costa-García, A., Fernández-Abedul, M.T., 2016. Biosens. Bioelectron. (in press). doi: 10.1016/j.bios.2016.06.068

Randles, J.E., 1948. Trans. Faraday Soc., 44, 327-338.doi: 10.1039/TF9484400327

Rackus, D.G., Shamsi, M.H., Wheeler, A.R., 2015. Chem. Soc. Rev. 44, 5320-5340. doi:10.1039/C4CS00369A

Rungsawang, T., Punrat, E., Adkins, J., Henry, C., Chailapakul, O., 2015. Electroanalysis 28, 462-468. doi:10.1002/elan.201500406

Russo, A., Ahn, B.Y., Adams, J.J., Duoss, E.B., Bernhard, J.T., Lewis, J. A., 2011. Adv. Mater. 23, 3426-3430. doi:10.1002/adma.201101328

Ruzgas, T., Csöregui, E., Emnéus, J., Gorton, L., Marko-Varga, G., 1996. Anal. Chim. Acta. 330, $123-$ 138. doi: 10.1016/0003-2670(96)00169-9

Santhiago, M., Henry, C.S., Kubota, L.T., 2014. Electrochim. Acta 130, 771-777. doi:10.1016/j.electacta.2014.03.109 
Sevcik, A., 1948. Collect. Czech. Chem. Commun. 13, 349-377 . doi: 10.1135/cccc19480349

Shahrokhian, S., Salimian, R., Kalhor, H.R., 2016. RSC Adv., 6, 15592-15598. doi: 10.1039/C5RA20907B

Shiroma, L.Y., Santhiago, M., Gobbi, A.L., Kubota, L.T., 2012. Anal. Chim. Acta 725, 44-50. doi:10.1016/j.aca.2012.03.011

Siegel, A.C., Phillips, S.T., Dickey, M.D., Lu, N., Suo, Z., Whitesides, G.M., 2010. Adv. Funct. Mater. 20, 28-35. doi:10.1002/adfm.200901363

Sjöberg, P., Määttänen, A., Vanamo, U., Novell, M., Ihalainen, P., Andrade, F.J., Bobacka, J., Peltonen, J., 2015. Sens. Actuator. B 224, 325-332. doi:10.1016/j.snb.2015.10.051

Songjaroen, T., Dungchai, W., Chailapakul, O., Laiwattanapaisal, W., 2011. Talanta 85, 2587-2593. doi:10.1016/j.talanta.2011.08.024

Streeter, I., Wildgoose, G.G., Shao, L., Compton, R.G., 2008. Sens. Actuat. B 133, 462-466.

Sun, Y., He, K., Zhang, Z., Zhou, A., Duan, H., 2015. Biosens. Bioelectron. 68, 358-364.

Sun, G., Ding, Y., Ma, C., Zhang, Y., Ge, S., Yu, J., Song, X., 2014. Electrochim. Acta 147, $650-656$. doi:10.1016/j.electacta.2014.09.149

Sun, Y., He, K., Zhang, Z., Zhou, A., Duan, H., 2015. Biosens. Bioelectron. 68, 358-364. doi:10.1016/j.bios.2015.01.017

Wang, J., Rivas, G., Cai, X., Dontha, N., Shiraishi, H., Luo, D., Valera, F.S., 1997. Anal. Chim. Acta 337, 41-48. doi:10.1016/S0003-2670(96)00395-9

Wang, S., Ge, L., Song, X., Yu, J., Ge, S., Huang, J., Zeng, F., 2012. Biosens. Bioelectron. 31, $212-218$. 
doi:10.1016/j.bios.2011.10.019

Wu, Y., Xue, P., Kang, Y., Hui, K.M., 2013. Anal. Chem. 125, 8661-8668. doi:10.1021/ac401445a 
Table 1. Bibliographic references for different carbon paper-based electroanalytical platforms specifying the application.

\begin{tabular}{|c|c|c|c|c|c|c|}
\hline Method & $\begin{array}{c}\text { Working electrode } \\
\text { material }\end{array}$ & Type of assay & Analyte & LOD & Comments & Ref. \\
\hline Screen-printing & $\begin{array}{c}\text { Carbon ink with } \\
\text { Prussian Blue }\end{array}$ & Enzymatic & Glucose & $4.9 \mathrm{mM}$ & $\begin{array}{l}\text { First paper-based elec- } \\
\text { trochemical platform }\end{array}$ & $\begin{array}{c}\text { Dungchai et } \\
\text { al., } 2009\end{array}$ \\
\hline $\begin{array}{l}\text { Screen- and inkjet- } \\
\text { printing }\end{array}$ & $\begin{array}{c}\text { Carbon graphite } \\
\text { paste modified with } \\
\text { polyanyline }\end{array}$ & Direct & Ascorbic acid & $30 \mu \mathrm{M}$ & $\begin{array}{l}\text { Impregnated with wax } \\
\text { paraffin for delimiting } \\
\text { hydrophobic areas }\end{array}$ & $\begin{array}{c}\text { Kit-Anan et } \\
\text { al.,2012 }\end{array}$ \\
\hline $\begin{array}{l}\text { Printing with a pen } \\
\text { in a plotter }\end{array}$ & $\begin{array}{l}\text { Graphite ink diluted } \\
\text { with solvent }\end{array}$ & $\begin{array}{l}\text { Enzyme im- } \\
\text { munoassay }\end{array}$ & $\begin{array}{l}\text { Malarial histi- } \\
\text { dine-rich protein }\end{array}$ & $2 \mathrm{pM}$ & $\begin{array}{l}\text { Sylanized paper. Folded } \\
\text { device. Immunoreaction } \\
\text { and electrochemical } \\
\text { detection spatially sepa- } \\
\text { rated }\end{array}$ & $\begin{array}{l}\text { Glavan et } \\
\text { al., } 2014\end{array}$ \\
\hline Pencil & $\begin{array}{l}\text { Graphite-based } \\
\text { pencil }\end{array}$ & Enzymatic & Glucose & $0.38 \mu \mathrm{M}$ & $\begin{array}{c}\text { Two-electrode system. } \\
\text { Pencil is external. Fol- } \\
\text { ded device. Separated } \\
\text { reaction and interaction } \\
\text { zones }\end{array}$ & $\begin{array}{l}\text { Santhiago et } \\
\text { al., } 2013\end{array}$ \\
\hline $\begin{array}{l}\text { Modified pencil } \\
\text { hand-drawing }\end{array}$ & $\begin{array}{l}\text { Graphite modified } \\
\text { pencil }\end{array}$ & Direct & $\begin{array}{l}\text { Hydrogen per- } \\
\text { oxide, cysteine }\end{array}$ & & $\begin{array}{l}\text { Conductive, modifier, } \\
\text { binding and hardening } \\
\text { agents are combined in } \\
\text { pencils }\end{array}$ & $\begin{array}{c}\text { Dossi et al., } \\
2014\end{array}$ \\
\hline Maskless deposition & Carbon ink & Bienzymatic & Glucose & $0.12 \mathrm{mM}$ & Autonomous platform & $\begin{array}{l}\text { Amor- } \\
\text { Gutiérrez et } \\
\text { al., } 2016\end{array}$ \\
\hline Nanomaterial-based & $\begin{array}{l}\text { Reduced graphene } \\
\text { oxide/CNTs }\end{array}$ & Direct & $\begin{array}{l}\text { Hydrogen per- } \\
\text { oxide }\end{array}$ & $10 \mathrm{nM}$ & $\begin{array}{l}\text { Deposition of Pt nano- } \\
\text { particles }\end{array}$ & $\begin{array}{l}\text { Sun et al., } \\
2015\end{array}$ \\
\hline Nanomaterial-based & $\begin{array}{c}\text { Aqueous dispersion } \\
\text { of CNTs }\end{array}$ & Enzymatic & Glucose & & $\begin{array}{l}\text { Coulometric determina- } \\
\text { tion. Electrofluidics. }\end{array}$ & $\begin{array}{l}\text { Hamedi et } \\
\text { al., } 2016\end{array}$ \\
\hline
\end{tabular}


Table 2. Determination of glucose in real samples with the proposed electrochemical platform and with a commercial enzymatic kit with spectrophotometric detection.

\begin{tabular}{ccc}
\hline Real sample & $\begin{array}{c}\text { Electrochemical platform } \\
(\mathrm{g} / \mathbf{1 0 0} \mathbf{~ m L})\end{array}$ & $\begin{array}{c}\text { Commercial kit } \\
(\mathrm{g} / \mathbf{1 0 0} \mathbf{m L})\end{array}$ \\
\hline Zero Cola & Below LOD & $0.010 \pm 0.001$ \\
Orange juice & $3.0 \pm 0.3$ & $2.9 \pm 0.2$ \\
Energetic beverage & $3.6 \pm 0.4$ & $3.5 \pm 0.2$ \\
Cola & $4.2 \pm 0.7$ & $4.1 \pm 0.3$ \\
\hline
\end{tabular}

Data are given as average $\pm \operatorname{SD}(n=4$ for the electrochemical system and $n=3$ for the spectrophotometric kit) 


\section{Caption for Figures}

Figure 1. Schematic representation of the fabrication of gold-sputtered paper-based electrodes: (A) Hydrophobic areas drawn with permanent marker, (B) Placement of plastic mask (top) and protective sheet (bottom) for the sputtering process, (C) Pattern obtained after the sputtering process (20 mA during 240 s) and mask removing. Cupper-foil connections were fixed with adhesive tape for upward (D) or downward (E) configurations.

Figure 2. Scheme of the wire-included plastic-based holder for downward and upward configurations: (A) basic design and dimensions of the holder with gold and platinum (grey gradient lines) external electrodes in upward mode. Tabs (i) fit into slits (ii) to close the structure and the paper-based device is inserted through the central slit (iii). (B) Closed holder with the paper electrode included for upward (top) and downward (bottom) modes.

Figure 3. (A) Cyclic voltammograms recorded in a $2 \mathrm{mM} \mathrm{K}_{4} \mathrm{Fe}(\mathrm{CN})_{6}$ solution in $0.1 \mathrm{M} \mathrm{PB}(\mathrm{pH}$ 7.0, 0.1 $\mathrm{M} \mathrm{KCl})$ at several scan rates $(10,25,50,75$ and $100 \mathrm{mV} / \mathrm{s})$ in the upwards mode employing the paperbased electrode as WE and wire electrodes as RE and CE. B) Effect of the scan rate on anodic and cathodic peak currents.

Figure 4. A) SEM images (x100) of the different employed paper substrates. Extraction tension: $20 \mathrm{kV}$; working distance: $10 \mathrm{~mm}$. Chr 1: Grade 1; G3MM: Whatman Grade 3MM; P81: Whatman phosphatemodified cation exchanger paper; DE81: Whatmandiethylaminoethyl-modified anion exchanger paper; MHF: Millipore Hi-Flow nitrocellulose membrane; PT-R5: Mdi polyester substrate; GF/Fand GFBR7L: Whatman and Mdi glass fiber substrates respectively. B) Bar chart with values of differential pulse voltammetry peak currents recorded in $2 \mathrm{mM} \mathrm{K}_{4} \mathrm{Fe}(\mathrm{CN})_{6}$ in $0.1 \mathrm{M}$ phosphate buffer $(\mathrm{pH} 7.0 ; 0.1 \mathrm{M}$ 
$\mathrm{KCl}$ ) depending on the relative behavior for different configurations. Amplitude is $25 \mathrm{mV}$ and step potential $5 \mathrm{mV}$. Error bars correspond to the standard deviation of three different devices.

Figure 5. A) Voltammograms (only anodic data are represented) obtained by cyclic voltammetry per-

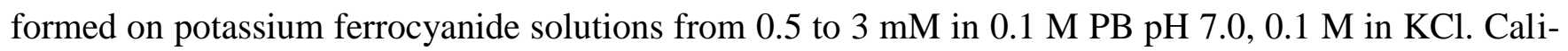
bration curves are shown in the inset. Each calibration point was made in a different gold paper-based working electrode using the same wire-based plastic holder (Au wire as reference electrode and Pt wire as counter electrode). Scan rate: $50 \mathrm{mV} / \mathrm{s}$. B) Chronoamperograms recorded for different concentrations of D-(+)-Glucose in $0.1 \mathrm{M}$ Tris- $\mathrm{HNO}_{3}$ buffer $\mathrm{pH} 7$ (up to down: 0, 0.1, 0.5, 1, 5, 10 and $15 \mathrm{mM}$ ) using gold-sputtered paper-based electrodes and the wire-based plastic holder. Calibration plots of the sensor acquired from chronoamperograms measured at $50 \mathrm{~s}$ are shown in the inset. Detection potential: $-0.2 \mathrm{~V}$ $v s$. gold pseudo-reference electrode. Data are given as average $\pm \operatorname{SD}(n=5)$. 